\title{
Development of a logical data model scheduling subsystem custom transport during XXII Olympic Winter Games
}

\section{Ismailov Andrey Rashidovich}

Russian Federation, Ph.D., Head of the department of development planning and monitoring systems. JSC "NPP Transnavigatsiya", 103051, Russian Federation, Moscow, B. Carriage Lane, 21, build. 1, Tel.: +7 (495) 783-54-85. http://www.transnavi.ru

aklerk@gmail.com

\section{Lvova Anna Bogdanovna}

Russian Federation, master of engineering and technology specialist.

JSC "NPP Transnavigatsiya", 103051, Russian Federation, Moscow, B. Carriage Lane, 21, build. 1, Tel.: +7 (495) 783-54-85. http://www.transnavi.ru

\section{ne-smotri-nalevo@yandex.ru}

\section{Ostroukh Andrey Vladimirovich}

Russian Federation, full member RAE, Doctor of Technical Sciences, Professor, Department of «Automated Control Systems».

Moscow Automobile \& Road construction State Technical University, 125319, Russian Federation, Moscow, Leningradsky prospekt, 64. Tel.: +7 (499) 151-64-12. http://www.madi.ru

ostroukh@mail.ru

\begin{abstract}
This paper proposes an approach to the development of a logical data model subsystem job scheduling for custom transport passengers within the automated dispatch control system ordered cargo.

Based on the study of foreign experience of the use of computer-based navigation systems in passenger services in the future form the requirements for establishing, within a subsystem of the passenger transport automated control system Logistics Transportation Center (LTC ACS).
\end{abstract}

Keywords: automated control system (ACS), process modeling and information processing systems, methods and management tools in the transport sphere, modeling, identification. 
ISSN 2306-1561

Автоматизация и управление в технических системах (АУТС) 2014. - №1.2(9). - C. 111-122.

DOI: $10.12731 / 2306-1561-2014-1-25$

УДК 004.9: 656.025

\section{Разработка логической модели данных подсистемы планирования заказных перевозок при проведении XXII Зимних Олимпийских Игр}

\section{Исмаилов Андрей Рашидович}

Российская Федерация, кандидат технических наук, начальник отдела разработки систем планирования и мониторинга.

ЗАО «НПП Транснавигация», 103051, Российская Федерация, г. Москва, переулок Каретный Б., д. 21, стр. 1, Тел.: +7 (495) 783-54-85. http://www.transnavi.ru

aklerk@gmail.com

\section{Львова Анна Богдановна}

Российская Федерация, магистр техники и технологии, специалист.

ЗАО «НПП Транснавигация», 103051, Российская Федерация, г. Москва, переулок Каретный Б., д. 21, стр. 1, Тел.: +7 (495) 783-54-85. http://www.transnavi.ru

\section{ne-smotri-nalevo@yandex.ru}

\section{Остроух Андрей Владимирович}

Российская Федерация, академик РАЕ, доктор технических наук, профессор кафедры «Автоматизированные системы управления».

ФГБОУ ВПО «Московский автомобильно-дорожный государственный технический университет (МАДИ)», 125319, Российская Федерация, г. Москва, Ленинградский проспект, д.64, Тел.: +7 (499) 151-64-12, http://www.madi.ru

\section{ostroukh@mail.ru}

Аннотация. В статье предложен подход к разработке логической модели данных подсистемы планирования заданий для заказных перевозок пассажиров в составе автоматизированной системы диспетчерского управления заказными перевозками.

На основе исследования зарубежного опыта использования автоматизированных навигационных систем транспортного обслуживания пассажиров в дальнейшем формируются требования для создания в рамках подсистемы управления пассажирским транспортом (ПУПТ) автоматизированной системы управления Логистического транспортного центра (АСУ ЛТЦ). 
Ключевые слова: автоматизированные системы управления (АСУ), моделирование процессов и систем обработки информации, методы и средства управления в области транспорта, моделирование, идентификация.

\section{1. Введение}

Организация Олимпийских Игр - является сложной, комплексной задачей. Подготовка крупнейшего спортивного события зимой 2014 г. в г. Сочи проводилась по 54 направлением, одним из которых является транспортное обеспечение всех участников и гостей Олимпиады.

В основе общего описания организации и управления транспортом, обслуживающим гостей и участников Олимпийских Игр лежит интермодальный подход, то есть совместное использование нескольких видов транспорта $[1-4,12,13$, 21]. Общая концепция системы управления интермодальными перевозками ориентирована на то, что прибытие зрителей, персонала и участников Игр осуществлялась с использованием возможностей железнодорожного, авиа, автомобильного и водного видов транспорта, а передвижение между олимпийскими объектами осуществляется при помощи железнодорожного и автомобильного видов транспорта, а так же канатной дороги.

Исходя из анализа предметной области можно выделить ряд сущностей, необходимых для создания заявки [5]. Данные сущности являются представлением соответствующих таблиц в базе данных и используются различными подсистемами автоматизированной системы помимо подсистемы планирования. В связи с этим атрибутов у сущностей может быть больше, чем требуется для того, чтобы успешно создать заявку на транспортное обслуживание, однако данные избыточные атрибуты могут быть необходимы для общего диспетчерского управления с помощью автоматизированной системы [5 - 24].

\section{2. Транспортные средства и водители}

Основной сущностью можно назвать Предприятия - Системы Автомобильных Перевозчиков (САП), осуществляющие выполнение заявок на транспортное обслуживание. Основными атрибутами данной сущности являются полное и сокращенное названия САП, адрес САП, а также идентификационный номер САП, назначаемый внутри базы. Идентификационный номер определяет уникальность предприятия.

Так как САП формируется из перевозчиков, их можно выделить отдельной сущностью с указанием названия организации-перевозчика, города и адреса, контактного телефона и идентификационного номера, выступающего первичным ключом. САП и перевозчики связаны между собой через транспортные средства и водителей, предоставленных перевозчиком определенному САП. Таким образом, еще одной сущностью выступают водители, работающие в САП. У каждого водителя есть 
свой табельный номер, фамилия, имя, отчество, контактный телефон для связи с ним, а также связь с САП и перевозчиком.

Транспортные средства должны выступать отдельной сущностью с указанием государственного номера, назначенного для ТС, гаражного номера, назначенного перевозчиком, данных о перевозчике и САП. Также необходима информация о вместимости транспортного средства - целочисленное значение количества пассажиров, способных с комфортом поместиться в ТС. Для учета багажа пассажиров необходимо ввести также параметр «тоннаж» - целочисленный параметр, описывающие количество мест багажа, которое ТС способно вместить. Учет тоннажа необходим при создании заданий на обслуживание, так как количество багажа у различных представителей клиентских групп может различаться и необходимо учитывать, способны ли выбранные транспортные средства перевозить указанное количество пассажиров с учетом их личных вещей и, например, спортивного оборудования.

Так как для обслуживания клиентских групп применяются различные виды транспорта (седаны, джипы, автомобили представительского класса, автобусы и прочие), виды транспорта имеет смысл вынести в отдельную сущность с указанием названия типа транспортного средства. Характеристикой вида ТС также может выступать максимально допустимая скорость для данного вида.

Связи данных сущностей можно представить в виде следующей диаграммы (рисунок 1):

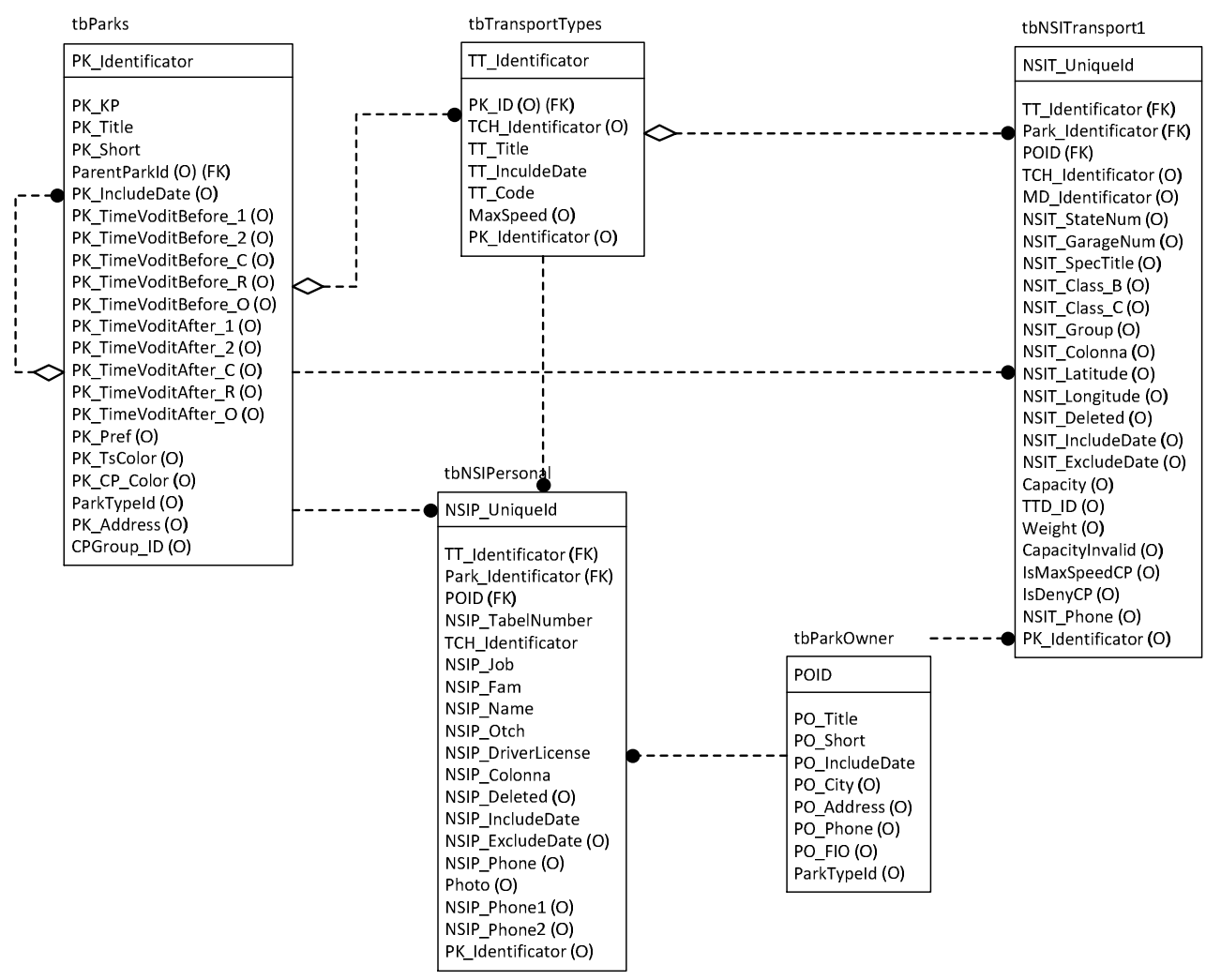

Рисунок 1 - Логическая модель данных транспортных средств и водителей 


\section{3. Контрольные пункты}

Отдельной группой сущностей можно выделить все, относящиеся к контрольным пунктам, между которыми осуществляются перевозки. Возникает необходимость в использовании сущности Контрольные пункты, с указанием полного и краткого названий контрольного пункта, указанием широты и долготы, на которой он располагается и типа контрольного пункта. Согласно требованиям ТДОИ, у каждого контрольного пункта есть свой тип:

- парк - контрольный пункт, соответствующий месту дислокации САП;

- инфраструктура - пункты общественного посещения гостей и участников Олимпийских Игр;

- посадка - пункт, где осуществляется процесс посадки пассажиров;

- д доставка - пункт, где осуществляется процесс высадки пассажиров;

- парковка - место стоянки транспортных средств.

Также во время Олимпиады было принято решение разделять объекты на спортивные и неспортивные. В большинстве случаев, к неспортивным объектам относятся САП, а все остальные контрольные пункты могут быть как спортивными, так и не неспортивными. Данное разделение принято называть видами объектов или контрольных пунктов. Согласно требованиям ОКОИ, виды КП могут добавляться и изменяться в процессе подготовки к Олимпиаде, поэтому необходимо вынести в отдельную сущность с атрибутами полного и кратного названий, описания вида КП и его номера в базе данных.

В описании предметной области было сказано, что для упрощения создания заданий при проезде по фиксированным контрольным пунктам их можно объединять в маршруты. Таким образом, возникает необходимость в создании сущности «Маршруты», содержащей информацию о названии маршрута, списке контрольных пунктов, входящих в маршрут и признака САП, к которому относится маршрут.

Связи сущностей, относящихся к Олимпийским объектам можно представить в виде схемы (рисунок 2).

Согласно требованиям к архитектуре подсистемы планирования, транспортное обслуживание может отличаться в различные моменты проведения игр: например, работа ТС во время Церемонии Открытия Игр и в обычный рабочий день Олимпиады по заявке. Во время анализа требований было выделено шесть видов заявок на обслуживание:

- рабочий день (заявка) - транспортировка пассажиров осуществляется в обычном режиме согласно их выбранному типу транспортной системы по предварительной заявке;

- рабочий день (по требованию) - предоставление соответствующего типу транспортной системы транспортного средства клиенту в обычном режиме по требованию;

- прибытие - предоставление транспортного средства для прибытия клиента на Олимпийские Игры; 
- убытие - предоставление транспортного средства для убытия клиента с Олимпийских Игр;

- открытие Игр - предоставление транспортного средства на период проведения церемонии открытия Олимпийских Игр;

- закрытие Игр - предоставление транспортного средства на период проведения церемонии закрытия Олимпийских Игр.

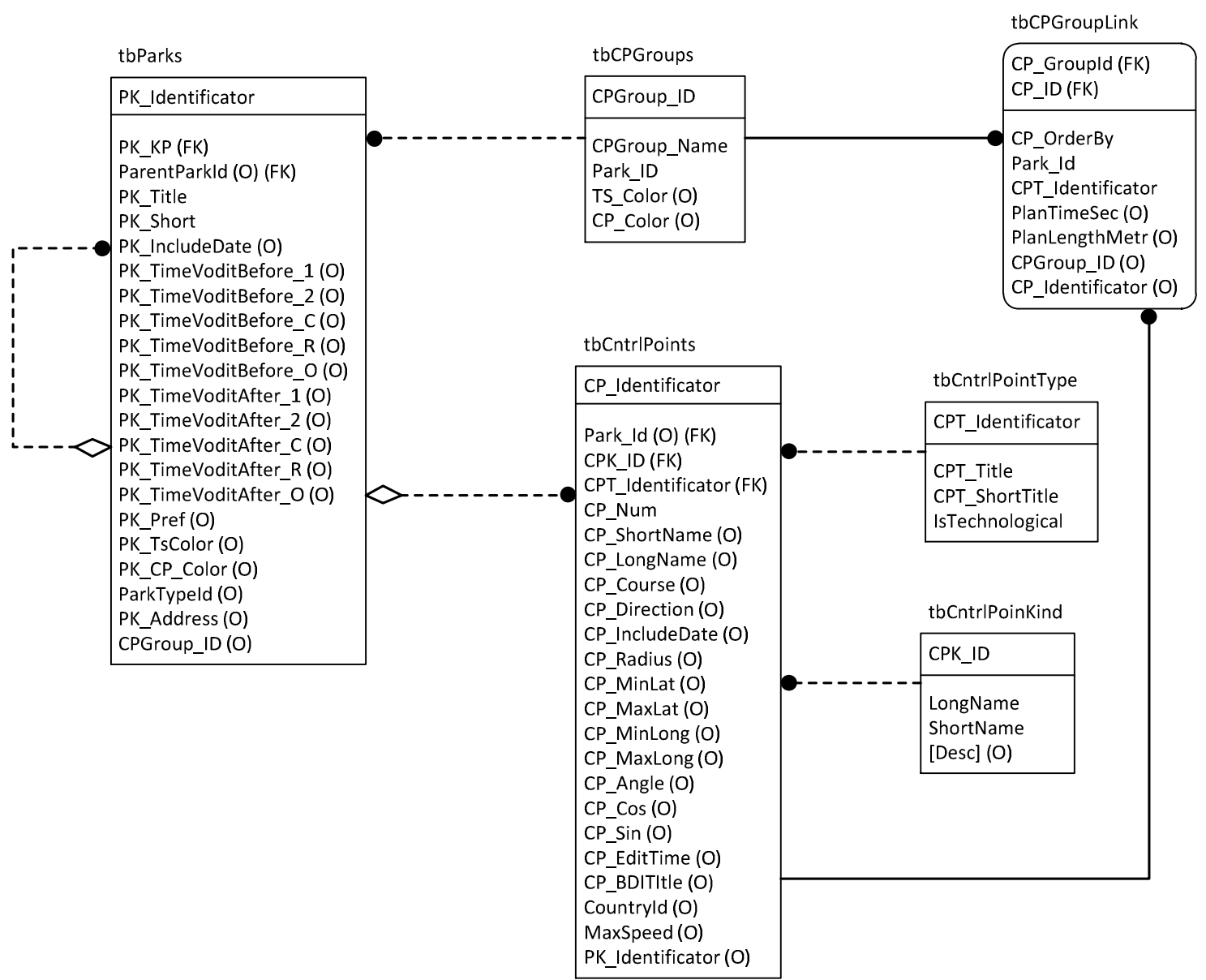

Рисунок 2 - Логическая модель связей сущностей, описывающих контрольные пункты

Различные виды заданий подразумевают различные варианты осуществления транспортного обслуживания клиентов согласно описанной выше бизнес-логике. Хранить данную информацию в базе можно при помощи сущности «Виды заданий», с указанием названия вида, его описания и идентификационного номера в БД.

Описанные ранее в предметной области наряды подразумевают возможность определения для транспортного средства вида задания, по которому оно будет работать в определенный день. Так как наряд должен иметь атрибут даты, на которую он сформирован, номера ТС и вида задания, по которому ТС работает в указанную дату, наряд можно выделить как отдельную сущность.

Типы транспортного обслуживания являются сущностью с атрибутами названия, приоритетностью и идентификационным номером. Приоритетность типов 
транспортного обслуживания определена согласно соглашению об уровне транспортного обслуживания и была описана выше. Бизнес-логика некоторых типов транспортного обслуживания совпадает (T1 и Т2, TA и TF), так что для упрощения процесса формирования заданий можно создать сущность «Группы транспортных систем», которая будет содержать сведения о входящих в группу типах транспортной систем в виде заголовка и номере транспортной группы, через который данная сущность будет связана с таблицей типов транспортных систем. Это понадобиться при создании заданий для перевозки различных клиентских групп, для которых допустимо изменение в предоставляемом уровне транспортного обслуживания.

Заявка на транспортное обслуживание для гостей и участников Игр принимается после при условии сообщения ими номера апгрейд-карты или номера аккредитации. Так как аккредитация выдается клиентам с указанием их персональных данных, а апгрейд-карта - без указания персональных данных, то возникает необходимость в разделении данных двух сущностей. Информацией об аккредитованных лицах может служить номер аккредитации, название организации, фактический и юридический адреса, контактные телефоны, ФИО контактного лица, номер аккредитации, дата начала и окончания аккредитации и данные о группе транспортных систем, по которым будет осуществляться обслуживание. Информация об апгрейд-картах формируется из дат начала и окончания действия карты, ее номере и группы транспортных систем. Также необходимо учитывать вероятность, что после выдачи аккредитация или апгрейд-карта может быть аннулирована, но клиент может быть не удален из общего списка. Для того чтобы проверять действительность аккредитации или апгрейд-карты пользователя необходим признак, возможно ли осуществление транспортного обслуживания для данного контрагента.

За каждым контрагентом может быть закреплено одно или несколько транспортных средств и их водителей. Данная сущность названа «Наряд контрагента» и содержит информацию о контрагенте, номере ТС и номере водителя.

По требованию ОКОИ, для формирования отчетности об интенсивности транспортного обслуживания в моменты проведения спортивных соревнований и прочих мероприятий было решено ввести сущность «Расписание мероприятий», содержащую данные с описание мероприятий, перечислений соревнований, проходящих в рамках данного мероприятия и времен начала и окончания мероприятия.

Стандартная заявка на обслуживания, переданная специалистами ОКОИ для обработки, содержит достаточно много параметров:

- тип заявки (прибытие/убытие);

- место прибытия/убытия;

- тип средства передвижения (самолет, поезд);

- дата и время прибытия/убытия;

- номер транспортного средства;

- количество человек;

- адрес отправной точки;

- страна; 
- тип клиентской группы (НОК, МОК и пр.);

- тип транспортной системы;

- количество людей с ограниченными возможностями;

- количество багажа;

- спортивная дисциплина;

- пункт назначения.

Также в заявке присутствует несколько дополнительных полей, которые необязательны к заполнению, но могут содержать полезную информацию, например, места пассажиров в транспортном средстве или тип ТС. При составлении заявки на перевозку клиентов часть данных становится избыточной. Так, например, важным остается время прибытия/убытия пассажира для установки времени подачи транспортного средства. Однако номер транспортного средства уже может не учитываться.

\section{4. Плановые задания}

На основе анализа данных в поступающих заявках был выделен список параметров, которые необходимо учитывать, при создании планового задания:

- дата и время создания задания для контроля создания заданий и аналитической отчетности;

- дата последнего редактирования задания - для анализа и отслеживания изменений в задании;

- плановое время начала - момент начала выполнения сформированного наряда одним или группой транспортных средств;

- плановое время окончания - момент окончания выполнения сформированного наряда;

- признак подтверждения задания - признак определяет, было ли передано задание водителю на выполнение и соответственно возникает ли необходимость в его контроле или данное задание было создано с целью дальнейшего редактирования и необязательно к выполнению и отслеживанию процессе выполнения;

- признак выполнения - признак определяет, было ли задание выполнено водителем;

- номер аккредитации - номер аккредитации клиента, в случае отсутствия которой указывается номер апгрейд-карты;

- номер апгрейд-карты - номер клиентской апгрейд-карты, в случае отсутствия которой указывается номер аккредитации;

- ФИО клиента - контактные данные о клиенте, в случае, если он указал номер апгрейд-карты;

- телефон - контактный телефон для связи с клиентом, если он указал номер апгрейд-карты; 
- тип транспортной системы - тип транспортной системы, по которой будет производиться транспортное обслуживание заказчика;

- тип задания - тип задания, согласно которому осуществляется транспортное обслуживание;

- САП - номер обслуживающего автотранспортного предприятия;

- заголовок задания - название задания, описывающего производимое транспортное обслуживание;

- комментарии и заметки - дополнительная информация, необязательная, но которая может потребоваться в определенные моменты при выполнении транспортного обслуживания.

В каждом плановом задании также должен присутствовать список контрольных пунктов, по которым будет осуществляться перемещение и список водителей, относящихся к данному заданию. Обычно, обязательным является наличие в заявке двух пунктов: подачи ТС и доставки клиента, однако их может быть и больше. Также, согласно требованиям ЛТЦ, контрольные пункты в задании могут быть обязательными и необязательными к посещению, что необходимо учитывать при формировании заявки. Количество транспортных средств зависит от отношения суммарной вместимости по заявке и вместимости транспортного средства. Таким образом, количество транспортных средств возрастает при увеличении числа заявленных пассажиров, a также c учетом требований по предоставлению специальных транспортных средств для людей с ограниченными возможностями. Решением данной проблемы является создание двух дополнительных сущностей с перечислением контрольных пунктов и транспортных средств соответственно. В них помимо информации о ТС и КП также содержится атрибут с номером задания, к которому они привязаны. Для контрольных пунктов из задания также обязательным является атрибут с номером следования конкретного контрольного пункта из списка в задании. Это необходимо для соблюдения правильной последовательности проезда между контрольными пунктами.

Для хранения контрольных пунктов из задания создана таблица tbTaskCP, в которой хранятся ID контрольных пунктов и ID задания, к которому они привязаны. Также ключевым полем является TC_OrderBy, которое отвечает за последовательность прохождения контрольных пунктов.

На рисунке 3 представлены основные таблицы, необходимые для формирования заявки на обслуживание: 


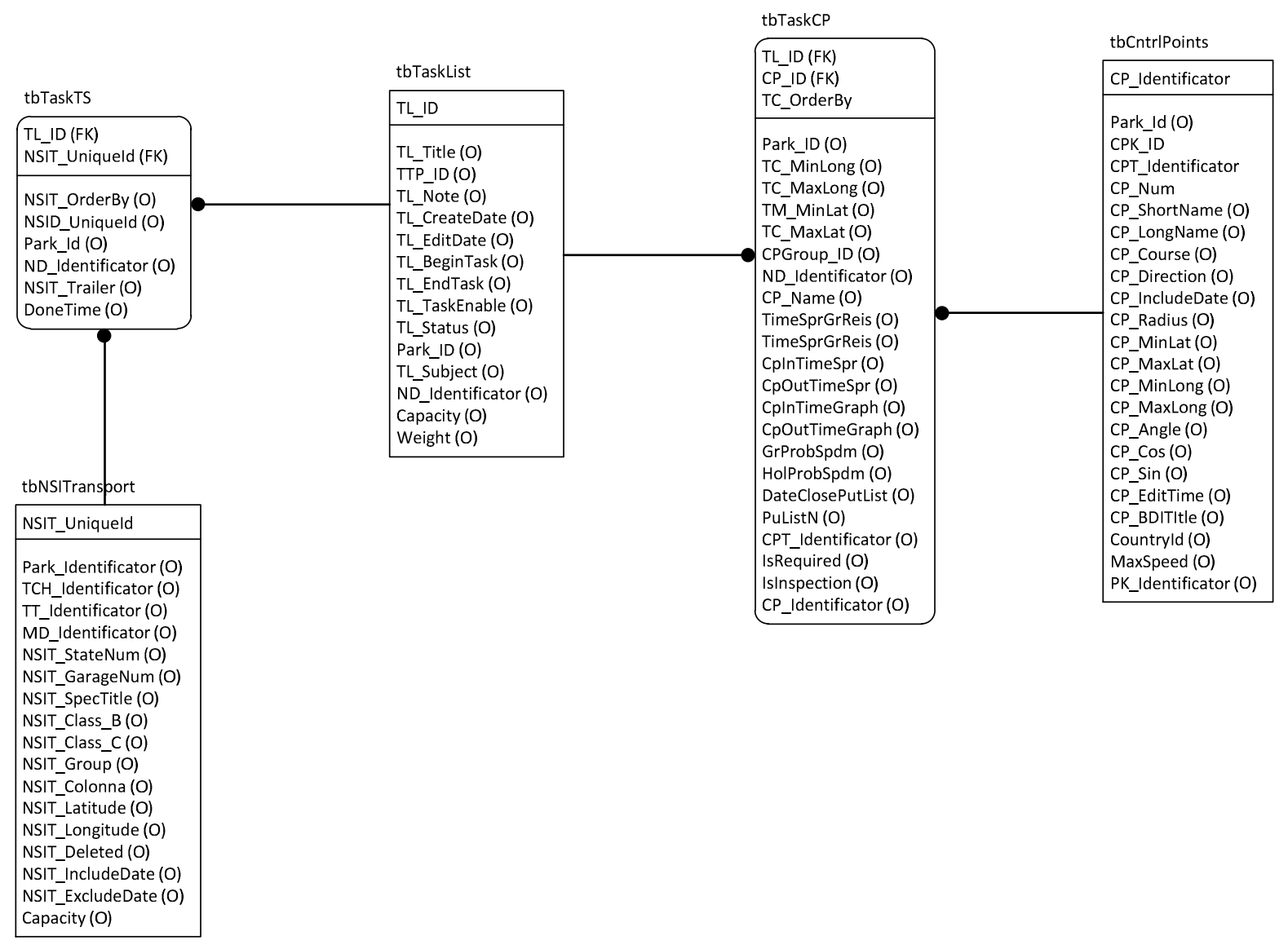

Рисунок 3 - Логическая модель связей сущностей относящихся к заданиям

\section{5. Заключение}

Проведено исследование предметной области. Проведен детальный анализ проектирования подсистемы планирования. Были выделены параметры задания и ряд ограничений, действующих при его создании.

Предполагается, что анализ предметной области, проведенный во время теоретических исследований, будет являться базисом для последующих экспериментальных исследований.

\section{Список информационных источников}

[1] Остроух А.В. Системы планирования перевозок. Программно-технологические решения по разработке системы планирования заданий для заказных пассажирских перевозок / А.В. Остроух, А.Б. Львова, А.Р. Исмаилов. Saarbrucken, Germany: LAP LAMBERT Academic Publishing, 2013. - 121 p. - ISBN 978-3-659-43619-2.

[2] Остроух А.В., Исмаилов А.Р., Львова А.Б. Проектирование программнотехнологических решений подсистемы планирования заданий для заказных перевозок пассажиров при проведении XXII Зимних Олимпийских Игр // Автоматизация и управление в технических системах. - 2014. - № 1.1. С. 98-111. DOI: $10.12731 / 2306-1561-2014-1-11$. 
[3] Исмаилов А.Р. Автоматизированная система планирования заданий для заказных перевозок пассажиров при проведении Олимпийских Игр / А.В. Остроух, А.P. Исмаилов, А.Б. Львова, А.Б. Николаев, П.Ю. Збавитель // Транспорт Российской Федерации. - 2013. - №6 (49). - С. 46-51.

[4] Исмаилов А.Р. Программно-технологические решения по разработке подсистем планирования заданий для заказных перевозок пассажиров при проведении Олимпийских Игр / А.В. Остроух, А.Р. Исмаилов, А.Б. Львова // Приборы и системы. Управление, контроль, диагностика. - М.: «Научтехлитиздат», 2013. №11. - С. 74-85.

[5] Суркова Н.Е. Методы проектирования информационных систем / А.В. Остроух, Н.Е. Суркова. - М.: РосHOУ, 2004. - 144 с. - ISBN 5-89789-021-8.

[6] Ефименко Д.Б. Автоматизированная навигационная система диспетчерского контроля и учета работы транспорта нефтедобывающих предприятий / А.И. Губанов, Д.Б. Ефименко, А.Б. Николаев, А.В. Остроух // Молодой ученый. - 2011. - №4. Т.3. - С. 18-21.

[7] Ефименко Д.Б. Развитие навигационной системы диспетчерского управления грузовым транспортом (на примере нефтедобывающих предприятий) / A.B. Остроух, Д.Б. Ефименко, С.А. Филатов // Автотранспортное предприятие. - 2011. №11. - С. 32-34.

[8] Ефименко Д.Б. Концепция автоматизированной навигационной системы диспетчерского контроля и учета работы транспорта нефтедобывающих и нефтеперерабатывающих предприятий / А.В. Остроух, А.Б. Николаев, Д.Б. Ефименко, А.И. Губанов // Автоматизация, телемеханизация и связь в нефтяной промышленности. - М.: ОАО «ВНИИОЭНГ», 2011. - №11. - С.12-14.

[9] Кузнецов И.А. Особенности реализации автоматизированной информационноаналитической системы центра планирования перевозок строительных грузов / А.В. Остроух, И.А. Кузнецов // Вестник МАДИ(ГТУ), - М.: МАДИ (ГТУ), 2008. Вып. 1(12). - С. 92-96.

[10] Куфтинова Н.Г. Имитационное моделирование управления транспортными потоками в мегаполисе / А.В. Остроух, Н.Г. Куфтинова // Автотранспортное предприятие. - 2010. - №12. - С. 41-42.

[11] Куфтинова Н.Г. Разработка информационно- логической модели транспортной сети мегаполиса / А.В. Остроух, Н.Г. Куфтинова // Бюллетень транспортной информации. - М.: Национальная ассоциация транспортников, 2013. - №1 (211). C. 23-26.

[12] Николаев А.Б. Информационные технологии в менеджменте и транспортной логистике: учебное пособие / А.Б. Николаев, А.В. Остроух. - Saint-Louis, MO, USA: Publishing House Science and Innovation Center, 2013. - 254 c. - ISBN 978-0615-67110-9.

[13] Остроух А.В. Автоматизация процессов диспетчерского управления городским пассажирским транспортом / М.Б. Польгун, А.Б. Николаев, Д.Б. Ефименко, А.В. Остроух // Промышленные АСУ и контроллеры. - М.: «Научтехлитиздат», 2013. №5. - C. 10-16.

[14] Остроух А.В. Научный подход к разработке автоматизированной навигационной системы диспетчерского контроля и учета работы транспорта нефтедобывающих и нефтеперерабатывающих предприятий / А.В. Остроух, А.Б. Николаев, Д.Б. Ефименко, С.В. Жанказиев // Автоматизированные системы управления и приборы автоматики. - Харьков: ХНУРЭ, 2011. - Вып. 157. - С. 48-58.

[15] Остроух А.В. Автоматизация планирования и управления транспортировкой продукции предприятий пищевой промышленности / А.В. Остроух, Н.Г. 
Куфтинова // Автоматика и вычислительная техника. - Рига: ИЭ и ВТ Латвийского университета, 2012. - №1. - С.57-67.

[16] Остроух А.В., Башмаков И.А., Польгун М.Б. Оптимизация параметров процессов автотранспортного обслуживания потребителей бетонных смесей // Автоматизация и управление в технических системах. - 2013. - № 4.2. - С. 189198. DOI: 10.12731/2306-1561-2013-4-39.

[17] Польгун М.Б. Анализ моделей оперативного диспетчерского управления городским пассажирским транспортом / М.Б. Польгун, А.В. Воробьева, А.В. Остроух // Молодой ученый. - 2011. - №4. Т.3. - С. 9-13.

[18] Порфирьева С.А. Автоматизированные информационные системы на автотранспортном предприятии / А.В. Остроух, К.А. Данчук, А.Б. Львова, С.А. Порфирьева, П.С. Якунин // В мире научных открытий. Серия «Проблемы науки и образования». - 2012. - №2.6 (26). - С.34-38.

[19] Исмаилов А.Р. Разработка архитектуры подсистемы планирования организации заказных перевозок клиентских групп при проведении XXII зимних Олимпийских Игр / А.В. Остроух, А.Р. Исмаилов, А.Б. Львова // Бюллетень транспортной информации. - М.: Национальная ассоциация транспортников, 2013. - №12 (222). - C. 3-10.

[20] Польгун М.Б. Анализ структуры информационного обеспечения автоматизированных систем диспетчерского управления городским пассажирским транспортом // Автоматизация и управление в технических системах. - 2012. - № 1. - С. 129-135.

[21] Ismailov A., Lvova A., Nikolaev A., Ostroukh A. Organization and Management of Transport Provided for the Guests and Participants of the Olympic Games // MiddleEast Journal of Scientific Research. 2013. Vol. 17 (8). pp. 1098-1104. DOI: 10.5829/idosi.mejsr.2013.17.08.12300.

[22] Ostroukh A.V., Kuftinova N.G. Automation of Planning and Management of the Transportation of Production for Food Processing Industry Enterprises // Automatic Control and Computer Sciences. - 2012. - Vol. 46. - No. 1. - pp. 41 - 48. DOI: 10.3103/S0146411612010063.

[23] Ostroukh A.V., Polgun M.B. Automation of processes supervisory control urban passenger transport // International Journal of Advanced Studies (iJAS). 2013. Vol. 3, Issue 3, pp. 3-9. DOI: 10.12731/2227-930X-2013-3-1.

[24] Ostroukh A.V., Polgun M.B. New approaches to development of automated supervisory systems of industrial enterprises transport // International Journal of Advanced Studies (iJAS). 2013. Vol. 3, Issue 4, pp. 3-9. DOI: 10.12731/2227-930X-2013-4-1. 